\title{
Denaturing gradient gel electrophoresis analysis for the detection of point mutations in the Chlamydia trachomatis major outer-membrane protein gene
}

\author{
C. SAYADA, E. DENAMUR, B. GRANDCHAMP, J. ORFILA* and J. ELION
}

Laboratoire de Biochimie Génétique and INSERM U 120, Hôpital Robert Debré, 48 Boulevard Sérurier, 75935 Paris Cedex 19 and *Laboratoire de Microbiologie, Faculté de Médecine, 80036 Amiens, France

\begin{abstract}
Summary. Fifty clinical strains of Chlamydia trachomatis were studied by denaturing gradient gel electrophoresis (DGGE) of bacterial DNA amplified by the polymerase chain reaction (PCR). The strains belonged to the three most commonly encountered serovars in developed countries--D, E and F. Six reference strains, including the serovar Da strain, were also studied. The DNA sequences explored encompassed the four variable domains (VDs) of ompl, the gene encoding the major outer-membrane protein (MOMP). The corresponding regions in the MOMP contain the species-, subspecies- and serovar-specific epitopes. The four distinct serovars were clearly differentiated by specific migration pattern. No sequence variations were observed among strains of serovar $F$. However, variant strains within serovars $\mathrm{D}$ and $\mathrm{E}$ were found, which exhibited migration patterns different from those of the reference strains and these were sequenced directly. According to the observed sequence variations, serovar $\mathrm{D}$ strains could be divided into three stable representative groups (D, D1 and D2). Two variants were identified among serovar E strains. No biological differences were observed for the variant strains in terms of growth properties, ecology or pathogenicity. All the nucleotide substitutions detected in the VDs were non-synonymous at the protein level and. for the serovar D strains, could account for differences identified by specific monoclonal antibodies. These substitutions could be involved in antigenic drift, driven by the immune pressure of the host, leading to the emergence of serovariants. The data may explain, in part, chlamydial infection recurrences and could have critical implications for developing rational vaccine strategies.
\end{abstract}

\section{Introduction}

Chlamydia trachomatis is an obligate intracellular prokaryote that causes trachoma, inclusion conjunctivitis, sexually-transmitted genital tract infections and neonatal pneumonitis in man. ${ }^{1}$ The most significant consequences are blindness, ectopic pregnancy, recurrent infections and infertility. Eighteen serovars of C. trachomatis have been identified by the microimmunofluorescence test with specific monoclonal antibodies (MAbs) to the major outer-membrane protein (MOMP). ${ }^{2.3}$ The MOMP is a complex and polymorphic surface antigen which contains serovar-, subspecies-, species- and genus-specific epitopes ${ }^{1-6}$ and T-cell epitopes.' Sequences of the MOMP-encoding gene (ompl) for all the C. trachomatis serovars have

Received 20 Sept. 1994 ; revised version accepted 9 Jan. 1995 Correspondence should be sent to Dr C. Sayada. been either completely or partially determined. ${ }^{8-17}$ Comparison of ompl sequences reveals that the MOMP contains five constant domains (CD I-V) separated by four variable domains (VD I-IV). The VDs are highly immunogenic and antibodies directed to epitopes located in these domains are thought to have a role in protective immunity. ${ }^{4,18}$ Thus, the MOMP is the most promising candidate antigen for a subunit vaccine. Therefore, precise characterisation of ompl genes is useful for studying the molecular epidemiology of C. trachomatis and also for designing a rational vaccine strategy. For such an application, the polymerase chain reaction (PCR), with a very small amount of unpurified $C$. trachomatis, is particularly suited.

Recently, genotyping schemes have been proposed for $C$. trachomatis based upon the differential restriction endonuclease mapping of PCR-amplified omp 1. ${ }^{1921}$ This strategy, in addition to predicting 
serotypes, can detect variants within a given serovar. Restriction endonuclease analysis however, identifies only a small part of ompl sequence variations, i.e., those affecting restriction sites. Direct sequencing of PCR-amplified ompl DNA fragments has also been applied to the molecular epidemiology of $C$. trachomatis. ${ }^{8,22,23}$ Because this approach is labourintensive for testing a large number of strains, denaturing gradient gel electrophoresis (DGGE) of ompl PCR products was evaluated as a screening method to detect rapidly sequence variations.

DGGE was first defined and developed by Fischer $e t$ $a l .{ }^{24,25}$ Myers et al. ${ }^{26,27}$ and by Lerman and Silverstein. ${ }^{28}$ It provides a simple method for identifying single base changes and insertions or deletions of a few nucleotides within relatively small fragments (up to $500 \mathrm{bp}$ ) of amplified DNA. This method is based on the principle that denaturation of double-stranded DNA retards its electrophoretic mobility in a polyacrylamide gel. Hence, when doublestranded DNA is run on a gel and meets with increasingly denaturing conditions, different DNAs show different mobilities, depending on the base composition of the lowest melting domain of the analysed DNA fragment. Attaching a GC-rich sequence to the amplified fragment of DNA through one of the PCR-primers ${ }^{29}$ has improved the possibility of detecting single base changes. Indeed, as a consequence, the explored region becomes relatively GCpoor and will be the lowest melting point domain analysed. As a complement to this technique, any PCR fragment with an abnormal migration pattern can be sequenced directly.

In this study, $50 \mathrm{C}$. trachomatis clinical strains belonging to serovars $\mathrm{D}, \mathrm{E}$ and $\mathrm{F}$, the most commonly encountered serovars in developed countries, were examined..$^{2,30,31}$ Five reference strains of the D, E and $\mathrm{F}$ serovars and a $C$. trachomatis $\mathrm{Da}$ strain, closely related to serovar D, were also included. Rapid assessment of $\mathrm{ompl}$ sequence variations was obtained by DGGE analysis of the four VDs and of their flanking regions. Any difference in migration pattern in these regions between the serovar reference strain and the clinical strains was investigated further by sequence analysis.

\section{Materials and methods}

\section{Bacterial strains}

Fifty $C$. trachomatis clinical strains were studied. These belonged to serovars D (11 strains), E (26) and F (13), respectively, according to the micro-immunofluorescence test with MAbs described by Moncan et $\dot{a} l .{ }^{31}$ except for three serovar D strains from Greece, which were serotyped as reported by Vretou et al..$^{32}$ Strains were selected randomly from a panel isolated between 1983 and 1991 in various cities of four European countries (Amiens, Nantes and Paris;
Lisbon; Parma; Athens) ${ }^{32}$ (J. Osfila, unpublished data). They had been collected from 50 patients suffering from superficial disease (urethritis, cervicitis or conjunctivitis) or invasive disease (epidydimitis or salpingitis). One of the strains (E/C-31) isolated in Paris was from a French man who had returned from Rio de Janeiro, Brazil, with conjunctivitis. In addition to the clinical strains, six reference strains were studied: D/IC-Cal-8 (USA), Da/TW-448 (Taiwan), E/Bour (USA), E/DK-20 (Denmark), F/MRC-301 (UK) and F/IC-Cal-3 (USA). The chlamydial organisms were cultured in egg yolk sacs, or in $\mathrm{HeLa}$ 229 or McCoy cells and prepared as described by Sayada et al..$^{21}$ The concentration of elementary bodies was $c .10^{3}-10^{8}$ inclusion forming units (ifu) $/ \mathrm{ml}$.

\section{DNA amplification}

DNA was obtained by lysis of 1-10 $\mu \mathrm{l}$ of unpurified chlamydial preparation in $250 \mu$ of a buffer containing $50 \mathrm{~mm} \mathrm{KCl}, 10 \mathrm{~mm}$ Tris- $\mathrm{HCl}$ (pH 8.3), $2.5 \mathrm{~mm} \mathrm{MgCl}_{2}$, Nonidet P-40 0.45\%, Tween $200.45 \%$ and proteinase $\mathrm{K} 60 \mu \mathrm{g} / \mathrm{ml}$. Positive-displacement pipettes were used to minimise sample carry-over and samples were prepared in a dedicated, externally vented hood. The preparation was incubated at $56^{\circ} \mathrm{C}$ for $60 \mathrm{~min}$, then proteinase $\mathrm{K}$ was inactivated by heating at $95^{\circ} \mathrm{C}$ for 10 min. $^{21}$ The PCR reaction mixture $(100 \mu \mathrm{l}$ final volume) contained: $10 \mathrm{~mm}$ Tris- $\mathrm{HCl}(\mathrm{pH} 8.3) ; 200 \mu \mathrm{M}$ each of dATP, dCTP, dGTP, dTTP; $0.2 \mu \mathrm{M}$ of each primer; $2.5 \mathrm{mM} \mathrm{MgCl}_{2} ; 50 \mathrm{mM} \mathrm{KCl}$; and 2.5 units of Thermus aquaticus DNA polymerase (Perkin ElmerCetus, Norwalk, CT, USA) and was overlayed with $100 \mu$ l of mineral oil. To improve specificity, the DNA preparation $(25 \mu \mathrm{l})$ was added last, after heating the amplification mixture at $80^{\circ} \mathrm{C} .{ }^{33}$ Samples were subjected to 30 cycles of amplification in a DNA Thermal Cycler (Perkin Elmer-Cetus). Cycling conditions were: denaturation, $1 \mathrm{~min}$ at $94^{\circ} \mathrm{C}$; primer annealing, $1 \mathrm{~min}$ at $56^{\circ} \mathrm{C}$; primer extension, $1 \mathrm{~min}$ at $72^{\circ} \mathrm{C}$. Oligonucleotides were synthesised by the phosphoramidite method on a DNA synthesiser (Applied Biosystems, Foster City, CA, USA). To verify the amplification, $5 \mu \mathrm{l}$ of the PCR reaction product were subjected to electrophoresis on agarose $2 \%$ gels stained with ethidium bromide and photographed under ultraviolet illumination. DNA molecular size marker $\mathrm{V}$ (Boehringer, Mannheim, Germany) was used.

\section{Computer analysis}

To optimise the gene amplification primers and to determine the parameters of DGGE analysis, the Melt87 and SQHTX computer algorithms written by Lerman and Sylverstein ${ }^{28}$ and OLIGO $^{34}$ were used. The computer simulations of DNA melting predicting the electrophoretic behaviour of the lowest melting point domains were performed on a model 70386 IBM PS2 computer equipped with a math co-processor. 
The program OLIGO was then used to double-check the PCR primers and predict the annealing temperature to be used for the PCR.

\section{$D G G E$}

The DGGE system was as described elsewhere. ${ }^{2 \pi .35}$ The electrophoresis apparatus (Pharmacia-LKB. Uppsala, Sweden) was kept at $60^{\circ} \mathrm{C}$ with a circulating water bath. The polyacrylamide denaturing gel $(14 \times 16 \times 0.75 \mathrm{~cm})$ consisted of a homogeneous polyacrylamide $8 \%$ matrix (stock solution of acrylamide : bisacrylamide $37 \cdot 5: 140 \%$ in $40 \mathrm{~mm}$ Trisacetate, $1 \mathrm{~mm}$ EDTA-TAE buffer $), 1$ in $170(\mathrm{v} / \mathrm{v})$ of ammonium persulphate $20 \%$ and 1 in $2000(\mathrm{v} / \mathrm{v})$ of $\mathrm{N}$. $\mathrm{N}, \mathrm{N}^{\prime}, \mathrm{N}^{\prime}$-tetramethylethylenediamine and contained a gradient of the denaturing agents, formamide and urea. Two different working gel solutions, corresponding to the lower and upper limits of each gradient, were prepared: i.e., $0 \%$ and $80 \%$ denaturant solutions consisting of acrylamide $8 \%$ in TAE buffer and acrylamide $8 \%$, de-ionised formamide $32 \%$ and $5.6 \mathrm{M}$ urea in TAE buffer. respectively. Gradient gels were formed by placing equal volumes $(12 \mathrm{ml})$ of these two working solutions in the communicating chambers of a conventional gradient maker. DNA test samples consisted of $10 \mu \mathrm{l}$ of the PCR product and $7 \mu \mathrm{l}$ of a solution containing Ficoll $40015 \%$ and bromophenol blue $1 \%$ in TAE buffer. Even temperature control of the gel was ensured by its complete immersion in the anodic buffer which was maintained under constant agitation. Circulation of the electrophoretic buffer from the anodic to the cathodic compartment was done with a peristaltic pump. Electrophoresis was performed for $3 \mathrm{~h}$ at $165 \mathrm{~V}$. The sequence and position of the oligonucleotide primers, size and $t_{m}$ of the amplified DNA, and concentration of the denaturant gradient in the electrophoretic gel are described in table I. After electrophoresis, the gel was stained with ethidium bromide for $10 \mathrm{~min}$ and photographed under UV illumination.

\section{Heteroduplexing}

Ten $\mu$ of the amplified products of each sample were mixed with $10 \mu \mathrm{l}$ of the amplified products of the reference strain of its corresponding serovar, boiled for $5 \mathrm{~min}$, incubated at $65^{\circ} \mathrm{C}$ for $5 \mathrm{~min}$ and loaded on to the denaturant gradient gel.

\section{Direct DNA sequencing}

Templates for direct sequencing were the doublestranded PCR products obtained with the CTU and CTL primers as described previously. ${ }^{21} \mathrm{PCR}$ products were purified with a Geneclean II Kit (Bio 101, La Jolla, CA, USA) and sequenced directly by the dideoxy chain termination method ${ }^{36}$ with T7 DNA polymerase (Sequanase, United States Biochemicals, Cleveland, $\mathrm{OH}$, USA) according to the manufacturer's in- structions. Sequencing primers were chosen in the conserved regions of the published sequences so as to obtain overlapping sequence data of 20-100 nucleotides, as described. ${ }^{14}\left[{ }^{35} \mathrm{~S}\right] \mathrm{dATP}$-labelled reaction products were separated by electrophoresis on polyacrylamide urea $6 \%$ gels and visualised by autoradiography. Each sequence showing inter-strain nucleotide differences was determined twice, from different DNA preparations.

\section{Results}

\section{Preliminary experiments}

DGGE analyses were performed on amplified fragments corresponding to VDs I, II, III and IV and their flanking regions. Primers were chosen by computational simulations so as to position the variable domain under study in the lowest melting point domain of the amplified fragment (table I). The GCCTU3 primer was degenerated to allow amplification of all $C$. trachomatis serovars. The melting temperature $\left(t_{\mathrm{m}}\right)$ of each explored domain was determined by the Melt87 program. The relationship between the predicted $t_{\mathrm{m}}$ and percentage denaturant is: percentage denaturant $=\left(t_{\mathrm{m}}-60\right) \times 3.3$. The range of the denaturant concentration gradient for electrophoresis was chosen to correspond to $5^{\circ} \mathrm{C}$ above and $5^{\circ} \mathrm{C}$ below the $t_{\mathrm{m}}$. Running times were determined experimentally for the four analysed regions ("travel time"), ${ }^{37}$ and confirmed by the SQHTX program. After $3 \mathrm{~h}$, fragments had already reached their retardation level in the gel and did not migrate much further if the electrophoresis was continued up to $7 \cdot 5 \mathrm{~h}$ (fig. 1). A running time of $3 \mathrm{~h}$ was chosen for the rest of the experiments because it corresponded to the time at which the bands were the best focused.

\section{Reproducibility and stability}

The six reference strains were used to test the reproducibility of the technique. For each strain the complete procedure, including DNA preparation, PCR amplification and DGGE analysis, was repeated independently 10 times for each VD. The same pattern was always observed for each of the tested strains.

Stability of the explored regions of the ompl sequence over time was tested by studying two independent batches of the same strains (E/DK-20 and $\mathrm{F} / \mathrm{MRC}-301)$. These two reference strains, originally isolated by $\mathrm{J}$. Treharne (Institute of Ophthalmology, London), were both analysed after repeated passage in cell cultures or in egg yolk sacs, in our own laboratory and separately in the laboratory of Dr F. Catalan (Institut Fournier, Paris). The two batches of each strain (from our laboratory and from Dr F. Catalan) produced the same DGGE patterns for the four VDs. Moreover, the four VDs were sequenced for each batch and no differences in the nucleotide sequences were found. Other evidence for the stability of the 
Table I. Sequence and position of the oligonucleotide primers, size and melting temperature $\left(t_{\mathrm{m}}\right)$ of the amplified DNA and concentration of the denaturant gradient in the electrophoretic gel

\begin{tabular}{|c|c|c|c|c|c|}
\hline Primer* & $5^{\prime}$-Sequence- $3^{\prime}$ & $\begin{array}{c}\text { Position } \\
\text { in } o m p 1 \\
\text { gene } \dagger\end{array}$ & $\begin{array}{l}\text { Amplified } \\
\text { fragment } \\
\text { size (bp) }\end{array}$ & $t_{\mathrm{m}}\left({ }^{\circ} \mathrm{C}\right)$ & $\begin{array}{l}\text { Concentrations } \\
\text { of the } \\
\text { denaturant } \\
\text { gradient }(\%) \\
\text { in the gel }\end{array}$ \\
\hline $\begin{array}{l}\text { GC-CTU1 } \\
\text { CTLI }\end{array}$ & $\begin{array}{l}\text { [GC]-ATGGTGACTTTGTTTTCGACCGT } \\
\text { CAAATATTCAATGTCATGCAAGCG }\end{array}$ & $\begin{array}{l}194-216 \\
389-366\end{array}$ & $234 / 237 \S$ & 71.5 & $20-50$ \\
\hline $\begin{array}{l}\text { CTU2 } \\
\text { GC-CTL2 }\end{array}$ & $\begin{array}{r}\text { GAATATTTGGGATCGTTTTGATGTA } \\
\text { [GC]-GGTTTAGATTGAGCATATTGGAAAG }\end{array}$ & $\begin{array}{l}381-405 \\
659-635\end{array}$ & 317 & 68 & $10-40$ \\
\hline $\begin{array}{l}\text { GC-CTU3 } \\
\text { CTL3 }\end{array}$ & $\begin{array}{l}\text { [GC]-CAATAAGCCTAAAGGA(A/G)TATGT(A/T)GG } \\
\text { GGCTGGGCTATACGAATCGTATC }\end{array}$ & $\begin{array}{l}708-731 \\
920-898\end{array}$ & 251 & $71 \cdot 5$ & $20-50$ \\
\hline $\begin{array}{l}\text { GC-CTU4 } \\
\text { CTL4 }\end{array}$ & $\begin{array}{l}\text { [GC]-GATGCCGATACGATTCGTATAGC } \\
\text { ATTGCAAGGAGACGATTTGCAT }\end{array}$ & $\begin{array}{c}892-914 \\
1042-1021\end{array}$ & $189 / 192 \S$ & 73 & $25-60$ \\
\hline
\end{tabular}

*Oligonucleotide primer pairs GC-CTU1, CTL1; CTU2, GC-CTL2; GC-CTU3, CTL3; GC-CTU4, CTL4 correspond to regions VDI-IV, respectively.

†Base numbering as in Peterson et al. ${ }^{12}$

$\ddagger[\mathrm{GC}]=$ GC-clamp of the following sequence: 5'GCGGGCGGGGCGGGGGCACGGGGGGCGCGGCGGGCGGC 3'. $\S$ Size for serovar $\mathrm{F}$ strains.

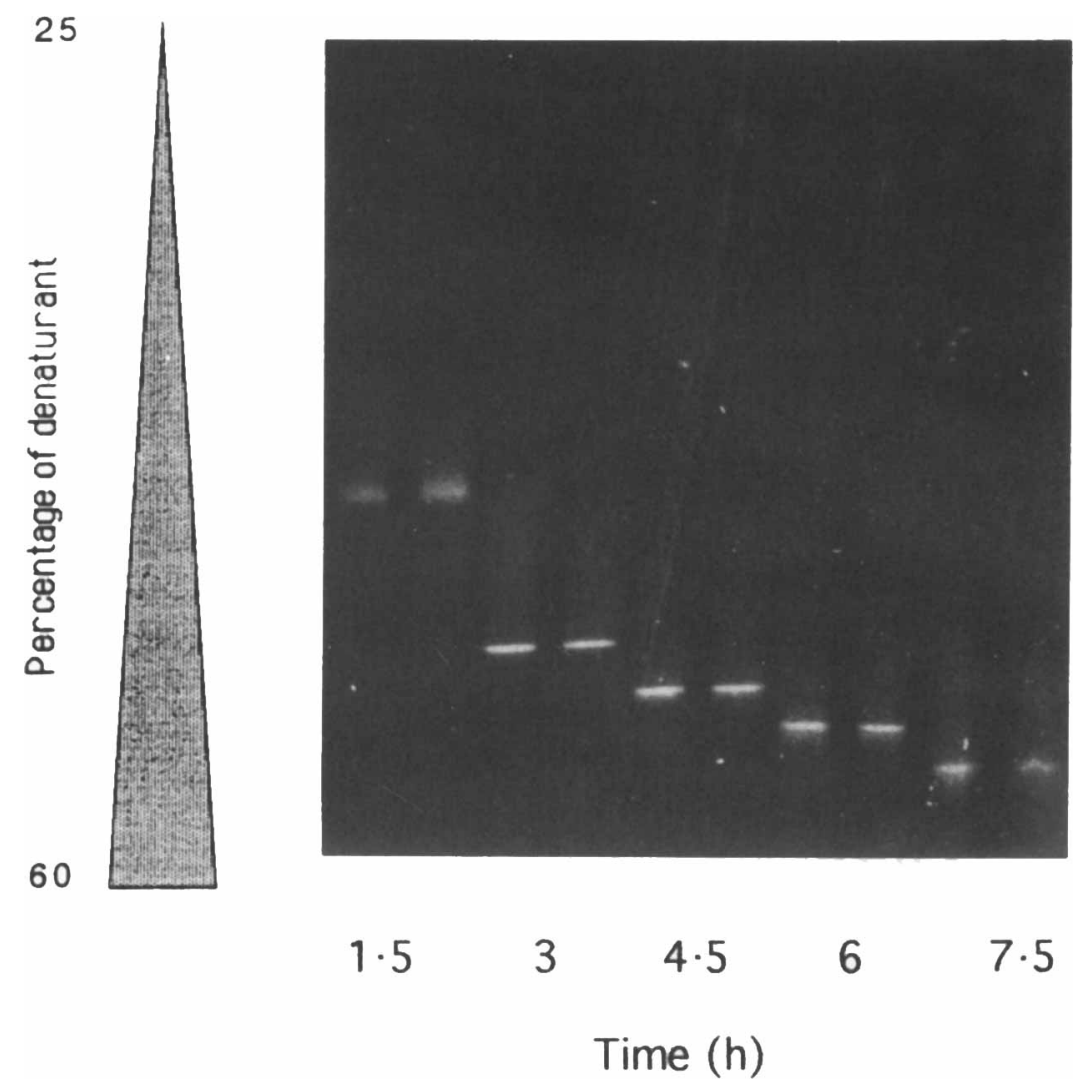

Fig. 1. Determination of the optimal running time for DGGE. The migration patterns of PCR-amplified omp I VDIV and its flanking regions are shown after electrophoresis for various times in a parallel $25-60 \%$ denaturant gradient gel. Samples of amplified fragments from strains $\mathrm{E} /$ Bour and $\mathrm{E} / \mathrm{DK}-20$ were loaded at intervals and electrophoresed at $165 \mathrm{~V}$ for the times indicated.

DNA regions studied is the fact that the nucleotide sequences obtained for the four other reference strains (Da/TW-448, D/IC-Cal-8, E/Bour and F/IC-Cal-3) were in perfect agreement with previously published data. ${ }^{8,12,16,17}$ Indeed, the strains studied were obtained from laboratories different from those in which the original sequences were determined, and thus had been passaged between the sequence determinations. Therefore, it seems that the explored regions, although coding for hypervariable domains, are stable over time in vitro for a given strain.

\section{$D G G E$ analysis of omp1 VDs and their flanking regions}

VDI region. The amplified fragment had a total size of 234 or $237 \mathrm{bp}$ depending on the strain (table I). It included an explored region consisting of 60 or $63 \mathrm{bp}$ 


\section{Da $\lfloor$ Serovar D $L \quad$ Serovar E $\lfloor$ Serovar F}
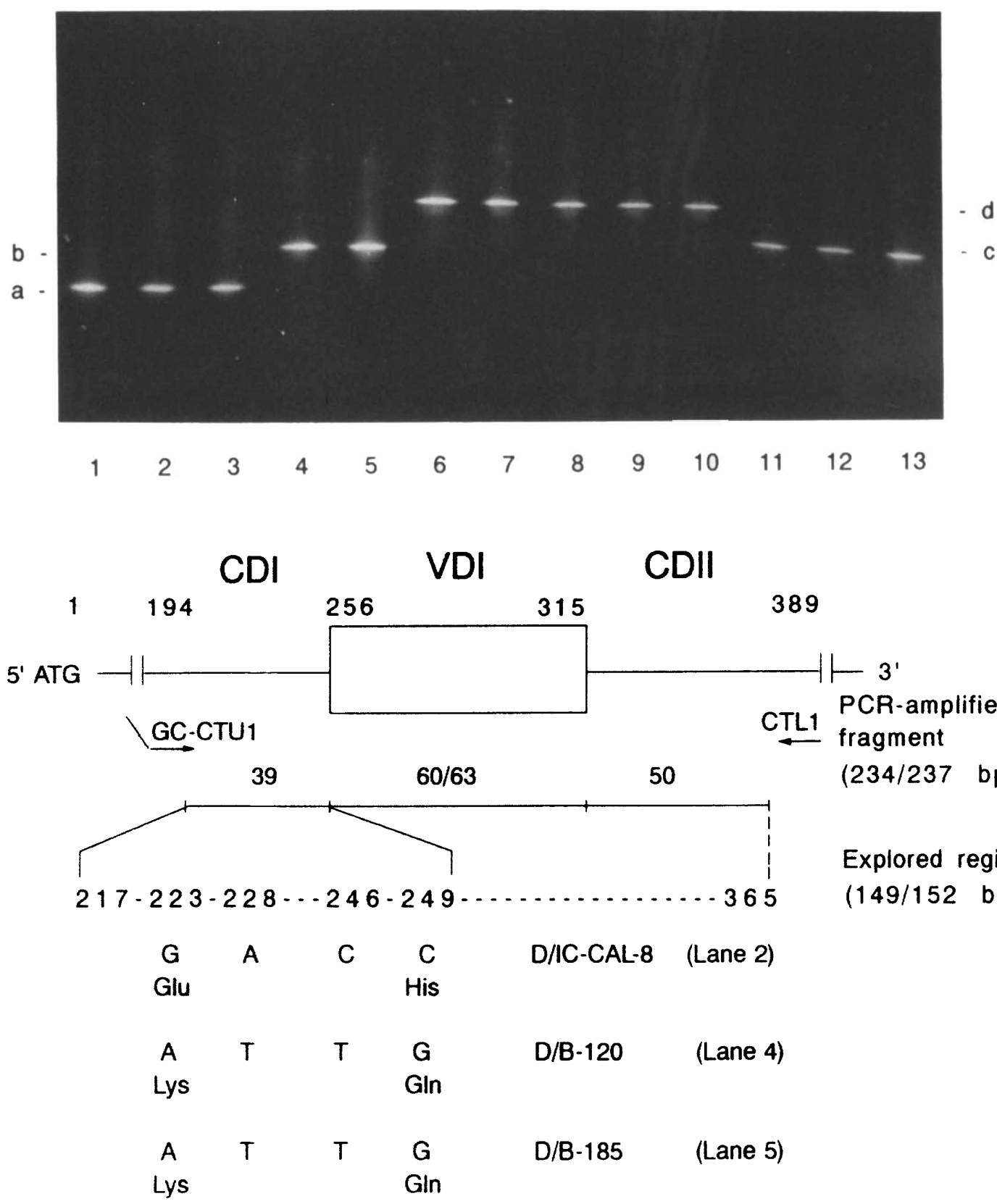

Fig. 2. DGGE analysis of the $o m p l \mathrm{VDI}$ and its flanking regions for $C$. trachomatis serovar $\mathrm{Da}, \mathrm{D}, \mathrm{E}$ and $\mathrm{F}$ strains in a parallel $20-50 \%$ denaturant gradient. Lane 1. Da/TW-448: 2, D/IC-Cal-8:3. D/B-129;4. D/B-120;5, D/B-185;6, E/Bour; 7, E/DK-20;8, E/B-116;9, E/C-31; 10, E/B-180;11. F/IC-Cal-3: 12. F/MRC-301; 13. F/B-186. Migration level a corresponds to lanes $1-3 ; \mathrm{b}$ corresponds to lanes 4 and $5 ; c$ to lanes $11-13 ; d$ to lanes $6-10$. Nucleotide substitutions between the serovar $\mathrm{D}$ strains migrating at levels a and $\mathrm{b}$, respectively, are shown in the bottom part of the figure, together with their position in ompl.

from VDI and $89 \mathrm{bp}$ from its flanking regions. Four migration patterns were observed: all the clinical strains of serovars $E$ and $F$ gave a migration pattern similar to that of the reference strains of the serovar (fig. 2; level $\mathrm{d}$ and $\mathrm{c}$; lanes $6-10$ and $11-13$ respectively). The serovar Da reference strain $\mathrm{Da} / \mathrm{Tw}-448$ produced a fragment migrating exactly as that generated by $\mathrm{D} / \mathrm{IC}$-Cal- 8 , the reference strain for serovar D (fig. 2; level a: lanes 1 and 2). However, some clinical strains of serovar D generated PCR products exhibiting a different migration pattern (fig.
2; level b; lanes 4 and 5) (table II). Thus the products from the D/IC-Cal-8 reference strain with migration pattern a and from all the strains with migration pattern $b$ were sequenced. For all strains of this latter type four single-base substitutions were found, as compared to the reference strain, D/IC-Cal-8 (fig. 2). The first substitution was a $\mathrm{G} \rightarrow \mathrm{A}$ change at nucleotide 223 which resulted in a Glu $\rightarrow$ Lys substitution at position 53 in the MOMP. The second and the third differences, $\mathrm{A} \rightarrow \mathrm{T}$ at nucleotide 228 and $\mathrm{C} \rightarrow \mathrm{T}$ at nucleotide 246 , were silent at the protein level. The 
Table II. DGGE patterns and amino acid substitutions exhibited by C. trachomatis strains of serovars $\mathrm{D}$ and $\mathrm{Da}$

\begin{tabular}{|c|c|c|c|c|c|}
\hline \multirow[t]{2}{*}{ Strain } & \multirow[t]{2}{*}{ VDI pattern } & \multirow[t]{2}{*}{ VDIV pattern } & \multirow{2}{*}{$\begin{array}{l}\text { Group } \\
\text { and } \\
\text { serovar }\end{array}$} & \multicolumn{2}{|c|}{$\begin{array}{c}\text { Amino } \\
\text { acid } \\
\text { substitutions }\end{array}$} \\
\hline & & & & CDs & VDs \\
\hline $\begin{array}{l}\text { D/IC-Cal-8 } \\
\text { D/B-129 } \\
\text { D/B-189 } \\
\text { D/Ev-389 }\end{array}$ & $\begin{array}{l}\mathrm{a} \\
\mathrm{a} \\
\mathrm{a} \\
\mathrm{a}\end{array}$ & $\left.\begin{array}{l}\mathrm{a} \\
\mathrm{a} \\
\mathrm{a} \\
\mathrm{a}\end{array}\right]$ & $\mathrm{D}$ & Prototype & Prototype \\
\hline $\begin{array}{l}\text { D/B-120 } \\
\text { D/A-43 } \\
\text { D/A-100 }\end{array}$ & $\begin{array}{l}\mathrm{b} \\
\mathrm{b} \\
\mathrm{b}\end{array}$ & $\left.\begin{array}{l}\mathrm{a} \\
\mathrm{a} \\
\mathrm{a}\end{array}\right]$ & D1 & $\begin{array}{l}\mathrm{Glu}_{53} / \text { Lys } \\
\mathrm{His}_{61} / \mathrm{Gln}\end{array}$ & Prototype \\
\hline $\begin{array}{l}\text { D/B-185 } \\
\text { D/A-72 } \\
\text { D/B-184 } \\
\text { D/Ev-688 } \\
\text { D/Ev-857 }\end{array}$ & $\begin{array}{l}b \\
b \\
b \\
b \\
b\end{array}$ & $\left.\begin{array}{l}d \\
d \\
d \\
d \\
d\end{array}\right]$ & $\mathrm{D} 2$ & $\begin{array}{l}\mathrm{Glu}_{53} / \text { Lys } \\
\mathrm{His}_{61} / \mathrm{Gln}\end{array}$ & $\mathrm{Ala}_{304} / \mathrm{Thr}$ \\
\hline $\mathrm{Da} / \mathrm{TW}-448$ & a & c ] & $\mathrm{Da}$ & Prototype & $\mathrm{Ala}_{311} / \mathrm{Thr}$ \\
\hline
\end{tabular}

fourth substitution, $\mathrm{C} \rightarrow \mathrm{G}$ at nucleotide 249 , produced a His $\rightarrow$ Gln difference at residue 61 in the MOMP. Migration pattern a observed for the $\mathrm{Da}$ strain is in agreement with that predicted from the published Da sequence. ${ }^{8,14}$ These nucleotide substitutions were all located in the $5^{\prime}$-flanking region included in the lowest melting point domain and none of them affected VDI.

VDII region. The amplified fragment included $63 \mathrm{bp}$ from VDII and $166 \mathrm{bp}$ from its flanking regions, for a total size of $317 \mathrm{bp}$ (table I). Three different migration patterns (a, b and c) were observed which corresponded to the $\mathrm{D}, \mathrm{E}$ and $\mathrm{F}$ serovars, respectively (fig. 3). No inter-strain variation was observed in this region. The amplified fragment of the serovar $\mathrm{Da}$ strain exhibited the same migration pattern (a) as that produced by the serovar $\mathrm{D}$ reference strain, $\mathrm{D} / \mathrm{IC}$ Cal-8. This result was in good agreement with the sequence data that showed identity in this region between D/IC-Cal-8 and Da/Tw-448. ${ }^{8,14}$

VDIII region. The amplified fragment included $42 \mathrm{bp}$ of VDIII and $124 \mathrm{bp}$ from its flanking regions, for a total size of $251 \mathrm{bp}$ (table I). Among serovar E strains, all strains exhibited migration pattern a, except strain E/B-116 which exhibited a different pattern (fig 4 ; level b, lane 3). For this strain, when compared with strain $\mathrm{E} /$ Bour, direct sequencing identified a single nucleotide $\mathrm{G}_{849} \rightarrow \mathrm{C}$ transversion which corresponds to $\mathrm{Met}_{261} \rightarrow$ Ile in the CDIV of the MOMP (fig. 4). Strains of serovar $\mathrm{F}$ all exhibited the same migration pattern c, distinct from the other patterns (fig. 4). Serovar D and Da strains could not be studied by this DGGE procedure because non-specific amplifications were obtained with the primer pair GC-CTU $\mathrm{C}_{3}$ and $\mathrm{CTL}_{3}$. However, direct sequencing of this region from serovar D prototype strains (D/IC-Cal-8, D/B-120 and $\mathrm{D} / \mathrm{B}-185)$ and the $\mathrm{Da} / \mathrm{TW}-448$ reference strain showed identical nucleotide sequences.

VDIV region. The amplified fragment included 90 or $93 \mathrm{bp}$ from VDIV and $17 \mathrm{bp}$ from its flanking regions for a total size of 189 or $192 \mathrm{bp}$, according to the strains (table I). Altogether, six distinct migration patterns were observed (fig. 5: a-f). Among serovar D strains, two patterns (a and d) were observed (table II). Direct sequencing of the amplified fragment was performed for the D/IC-Cal-8 reference strain (level a) and for the five strains exhibiting pattern d (table II). Results are shown in fig. 5. A $G_{976} \rightarrow$ A substitution was found for the strains exhibiting migration pattern $\mathrm{d}$, compared with the D/IC-Cal-8 sequence. This nucleotide difference produces an $\mathrm{Ala}_{304} \rightarrow \mathrm{Thr}$ substitution located in the MOMP VDIV. As expected from its published sequence, ${ }^{8,14}$ the Da strain exhibited a specific migration pattern c. Two nucleotide differences with D/IC-Cal-8 were present in VDIV : a $\mathrm{T}_{939} \rightarrow \mathrm{C}$ synonymous substitution at the protein level and a $\mathrm{G}_{997} \rightarrow \mathrm{A}$ producing an $\mathrm{Ala}_{311} \rightarrow$ Thr substitution. All the strains of serovar E exhibited a similar migration pattern (b), with the exception of strain E/C-31 which generated a different migration pattern, e. Direct sequencing of the analysed region of strain E/C-31 identified three nucleotide substitutions compared to the $\mathrm{E} /$ Bour sequence, all located in the MOMP VDIV. The first one, $\mathrm{a}_{934} \rightarrow$ A produced an $\mathrm{Ala}_{290} \rightarrow \mathrm{Thr}$ substitution. The second and third ones were a $\mathrm{G}_{991} \rightarrow \mathrm{C}$ and a $\mathrm{C}_{992} \rightarrow \mathrm{G}$ change, respectively, and correspond to an $\mathrm{Ala}_{309} \rightarrow \mathrm{Arg}$ substitution in the MOMP. A single migration pattern (f) was observed for all the strains of serovar $F$.

The results show that the strains of serovar $\mathrm{D}$ could be divided into three groups (D, D1 and D2; table II) according to the DGGE patterns obtained for the VDI and VDIV regions. Strains of group D1 differed from the reference strain by four substitutions in CDI, two of them being non-synonymous at the protein level. Strains of group D2 present the same substitutions in CDI but also an additional non-synonymous substitution in VDIV. Two variant strains of serovar E were identified that differed from the reference strain by one and three non-synonymous substitutions in 


\section{Da $\mid$ Serovar D | Serovar E $\mid$ Serovar F}

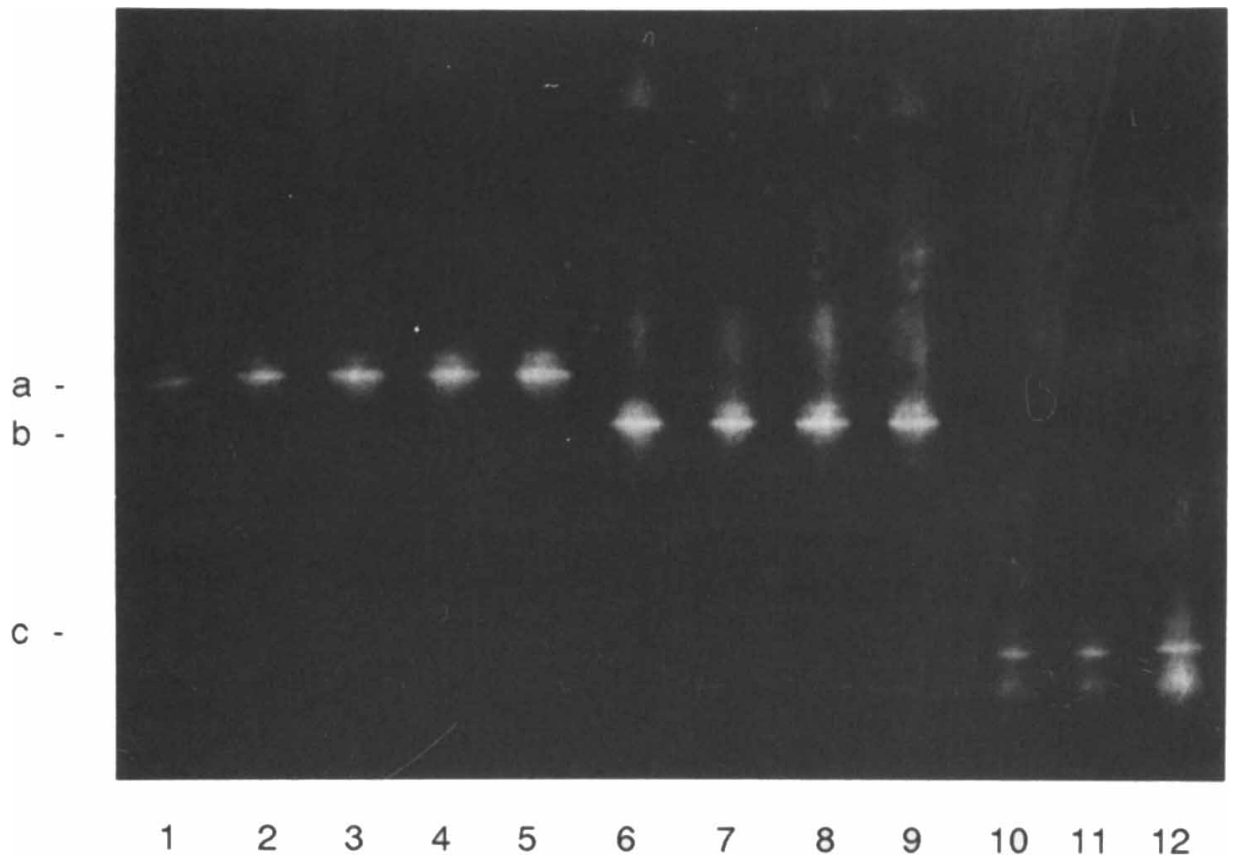

\section{VDII CDIII}

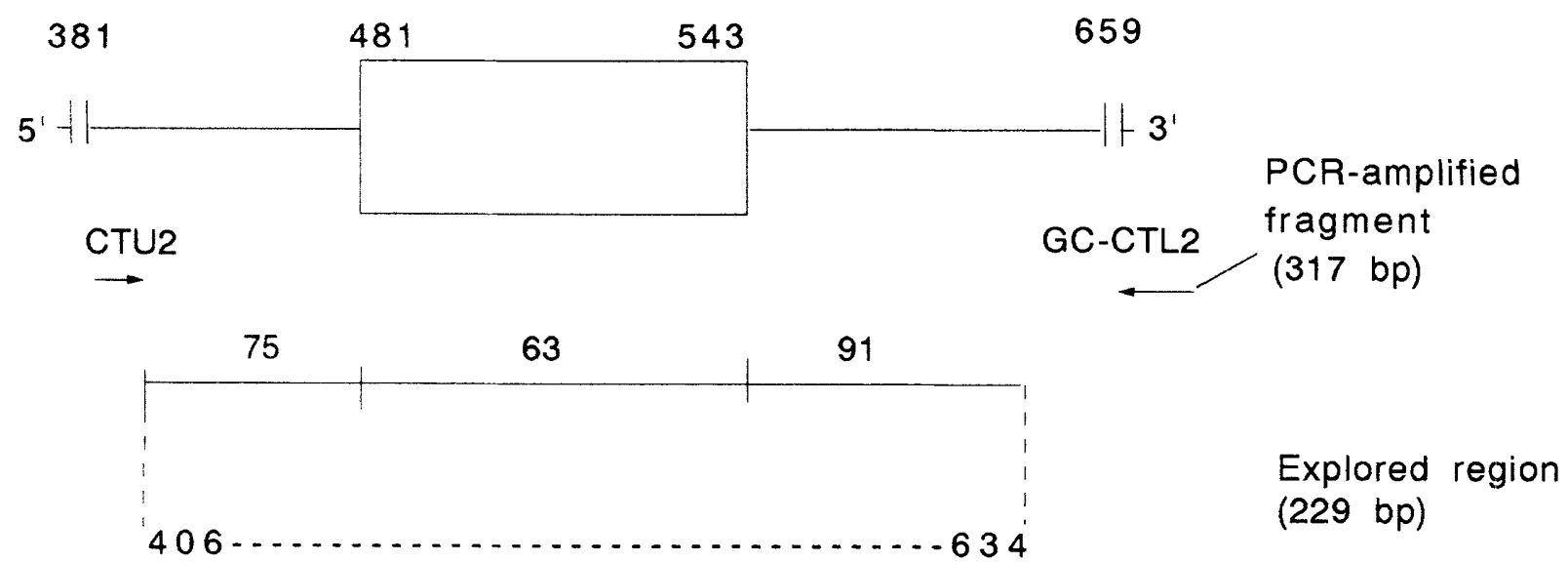

Fig. 3. DGGE analysis of $o m p /$ VDII and its flanking regions for $C$. trachomatis serovar Da, D, E and F strains in a parallel $10-40 \%$ denaturant gradient. Lane 1, Da/TW-448;2, D/IC-Cal-8;3, D/B-129;4. D/B-120; 5, D/B-185; 6, E/Bour; 7, E/DK-20;8, E/B-116;9, $\mathrm{E} / \mathrm{C}-31 ; 10, \mathrm{~F} / \mathrm{IC}-\mathrm{Cal}-3 ; 11 . \mathrm{F} / \mathrm{MRC}-301: 12$. F/B-186. Migration level a corresponds to lanes $1-5 ;$ migration level b to lanes $6-9 ;$ migration level $\mathrm{c}$ to lanes $10-12$

CDIV and VDIV, respectively. No differences were observed among strains of serovar $\mathrm{F}$.

\section{Heteroduplex analysis}

To increase the resolution of detection of nucleotide variation by the DGGE analysis described above, the heteroduplexing procedure proposed by Traystman $e t$ $a l .{ }^{3 \star}$ was used for molecular analysis of factor VIII. All the strains were tested for the VDII and VDIV regions by this procedure. For heteroduplexing, the PCR product from each strain studied was mixed individually with the PCR product of the reference strain of the corresponding serovar that was chosen for sequence determination. When PCR products with different migration patterns (i.e., corresponding to different nucleotide ompl sequences) were mixed, differences between the two PCR products generated slow migrating heteroduplex bands upon denaturation and renaturation of the mixture (fig. 6). In contrast, mixing PCR products with identical migration patterns obtained from strains with identical sequences did not produce slow migrating bands. One such example is shown in fig. 6 (lane 6). None of the clinical strains sharing an identical migration pattern in the standard DGGE analysis showed heteroduplexes with this additional procedure.

\section{Analysis of identical DGGE patterns}

To determine whether differences in DNA sequence could be missed when strains exhibit identical DGGE 

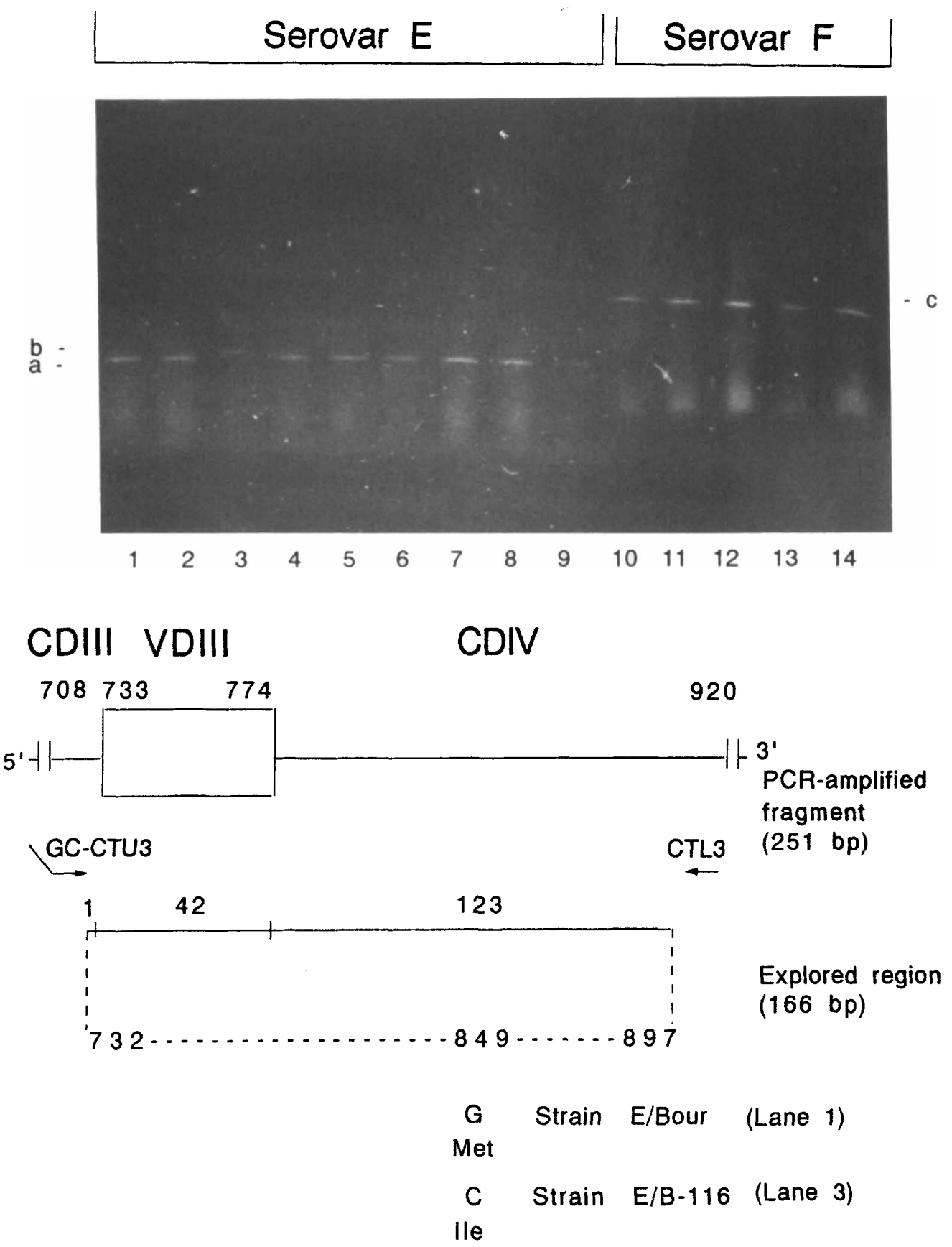

Fig. 4. DGGE analysis of ompl VDIII and its flanking regions for $C$. trachomatis serovar $\mathrm{E}$ and $\mathrm{F}$, strains in a parallel $20-50 \%$ denaturant gradient. Lane 1, E/Bour;2, E/DK-20;3, E/B-116;4, E/C-31; 5, E/B-180;6, E/A-65; 7, E/A-27;8, E/B-141;9, E/C-87; 10, F/B-133; 11. F/IC-Cal-3; 12, F/MRC-301; 13, F/B-186;14, F/B-140. Migration level a corresponds to lanes $1,2,4-9 ;$ migration level b to lane $3 ;$ and migration level $\mathrm{c}$ to lanes $10-14$. The nucleotide substitution differentiating migration levels a from $b$ is shown in the bottom part of the figure.

patterns, each VD region of ompl of six serovar D and Da strains exhibiting identical DGGE pattern was sequenced. No sequence differences were found between strains exhibiting identical DGGE patterns.

\section{Discussion}

DGGE of PCR-amplified genomic DNA is currently used for the detection and the screening of mutations or polymorphisms in human genetic disorders including haemophilia, ${ }^{35.38,39} \beta$-thalassaemia ${ }^{40,41}$ or cystic fibrosis. ${ }^{42}$ All reports agree on the usefulness and power of this approach. The major advantage of
DGGE is its simplicity, since neither hybridisation nor enzymic digestion are required. Most importantly, it is possible to detect sequence variations in the DNA region under investigation without preconceived ideas on what these sequence variations might be.

To be efficient as a general tool, DGGE analysis of amplified fragments from many different bacterial strains requires that the amplification primers are chosen in highly conserved regions so that amplification is possible with a single set of amplimers. Moreover, to be able to distinguish between closely related strains, the low melting point domain in the amplified fragments should include a highly polymorphic region. Omplis particularly well suited to this 


\section{Da $\mid$ Serovar D L Serovar E L Serovar F}
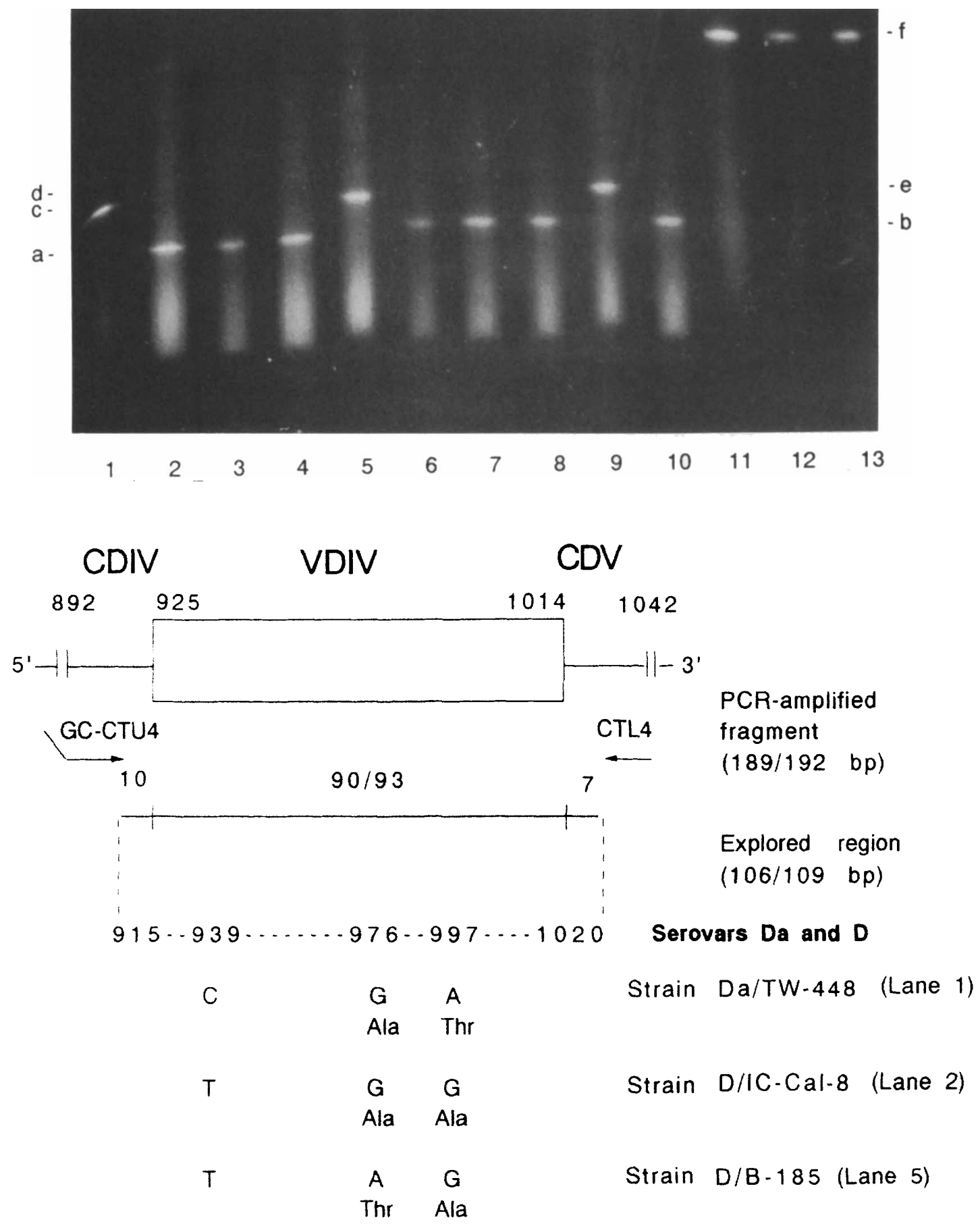

$915-934 \cdots \cdots \cdot 991992 \cdots 1020 \quad$ Serovar $E$

$\begin{array}{ccc}\text { G } & \text { G C } & \text { Strain E/Bour (Lane 6) } \\ \text { Ala } & \text { Ala } & \\ \text { A } & \text { C G } & \text { Strain E/C.31 (Lane 9) } \\ \text { Thr } & \text { Arg } & \end{array}$

Fig. 5. DGGE analysis of omp/ VDIV and its flanking regions for $C$. trachomatis serovar Da, D, E and F strains in a parallel $25-60 \%$ denaturant gradient. Lanes are numbered as in fig. 2. Migration level a corresponds to lanes 2-4; migration level b to lanes 6-8 and $\mathbf{1 0}$; migration level c to lane 1 ; migration level d to lane 5; migration level e to lane 9; and migration level f to lanes 11-13. Nucleotide substitutions between strains of the serovars $\mathrm{Da}, \mathrm{D}$ and $\mathrm{E}$, migrating at different levels (a-e) are shown in the bottom part of the figure. 

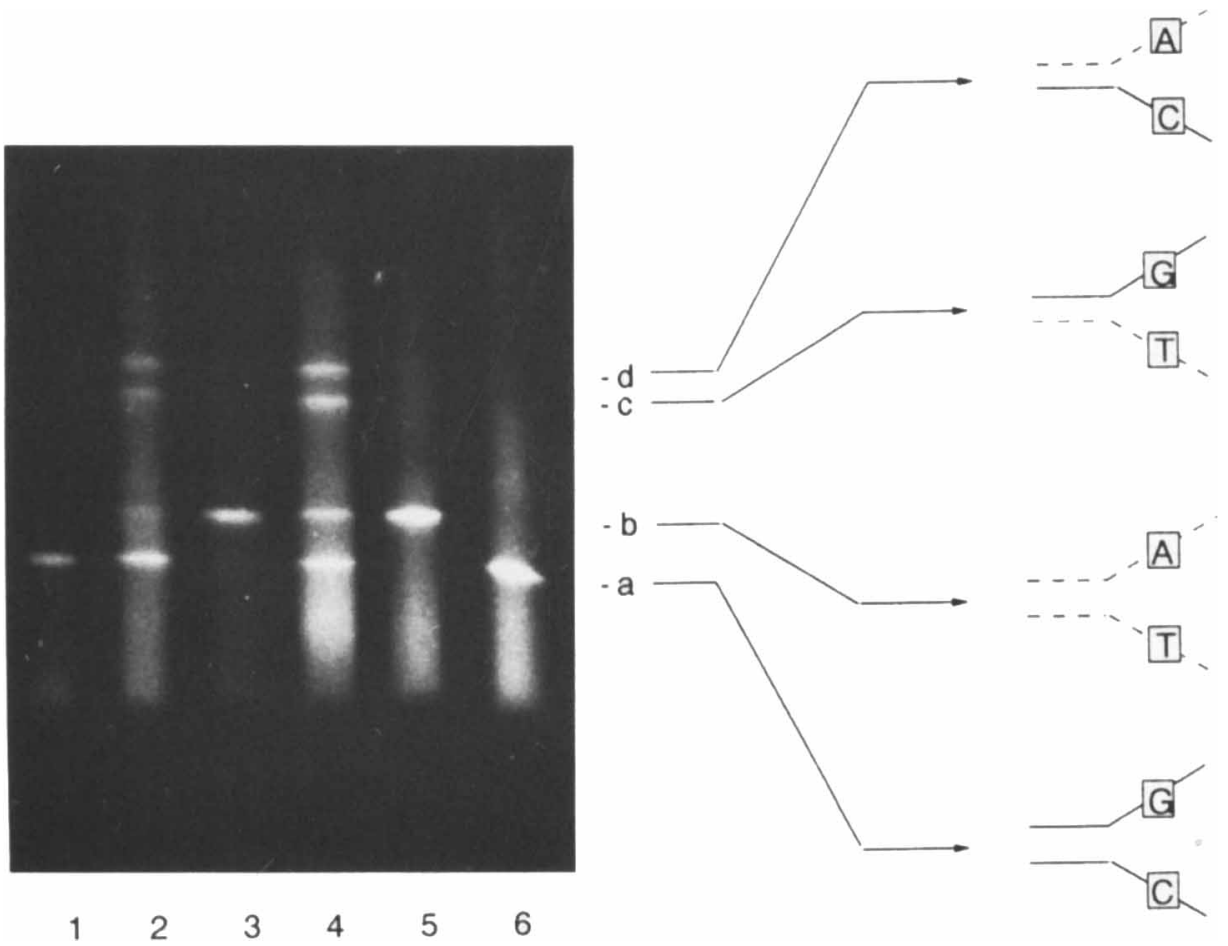

Fig. 6. Heteroduplexing procedure used for the DGGE analysis of VDIV in C. trachomatis serovar D strains. Lane 1, D/IC-Cal-8; 2, mixture of D/IC-Cal-8 and D/B-185; 3, D/B-185; 4, mixture of D/IC-Cal-8 and D/B-184; 5, D/B-184; 6, mixture of D/IC-Cal-8 and D/B-120. Migration levels $\mathrm{a}$ and $\mathrm{b}$ correspond to the homoduplexes and migration levels $\mathrm{c}$ and $\mathrm{d}$ to the heteroduplexes as indicated on the right.

purpose with alternating CDs and VDs, and data from this study illustrate this point. The homologous amplified fragments from strains of distinct serovars migrated at distinct levels, for all four regions studied, thus clearly differentiating one serovar from another. This was expected because the VDs of ompl may exhibit differences of up to $15 \%$ in their nucleotide sequences between serovars. ${ }^{16}$ However, DGGE also readily identified sequence variations within a given serovar, i.e., between closely related strains. It is well known that, in DGGE, heteroduplexes observed with diploid heterozygous genomes enhance the sensitivity of detection for some substitutions. ${ }^{38,40-42}$ In this study, no additional nucleotide substitutions were detected when the heteroduplexing procedure was used. Thus, since heteroduplexing is a tedious procedure with multiple manipulations, there is no need to include it in large epidemiological screenings. As already discussed by Lerman and Silverstein ${ }^{28}$ optimisation of the procedure by careful computerassisted modelling is undeniably the crucial step to achieve maximal resolution of the standard DGGE analysis. Our data suggest that DGGE is reasonably good at detecting sequence variation in the prokaryotic genome and, at the present time, is much simpler than systematic sequencing. Moreover, the exquisite sensitivity of the PCR procedure allows the application of this technique directly to clinical specimens (data not shown) as already shown for direct sequence analysis. ${ }^{23}$

Two variant strains of serovar $E$ were identified; one was from Brazil and the other from France. Much more interesting is the fact that DGGE analysis revealed a hitherto unsuspected heterogeneity among strains of serovar D. This heterogeneity was different from that observed in serovar $E$ since it did not identify a small number of variants but divided strains of serovar D into three stable groups of equal importance (table II). Indeed, these strains were isolated over a period of 9 years from three different cities in France for group D1, and from four different European countries for strains of groups D and D2. The reference strain of group D was from the USA. In sharp contrast, strains of serovar $F$ were homogeneous, although they were collected over the same period of time and from similar origins in Europe. Furthermore, the two corresponding reference strains were from the USA and UK.

No correlation was found between the three groups of serovar D strains or the serovar E variants and the observed pathology or obvious peculiarities in growth properties. Thus, the biological significance of such a sequence heterogeneity remains unclear. However, a detailed analysis of the observed sequence variations revealed some interesting features concerning the antigenic epitopes at the cell surface of $C$. trachomatis. In the VD regions, nucleotide variations were found in VDIV only. The absence of variation in other VDs is somewhat surprising. VDII, for instance, was the most variable domain from serovar to serovar and also the target of neutralising antibodies. Thus, because of immune pressure, one might have expected to observe variations in this region even within a given serovar. From an epidemiological point of view, the results show that VDII should not be considered as a prime target for strain differentiation within a given serovar. Of the six nucleotide variations observed in VDIV, five 
correspond to non-conservative amino acid substitutions located in the vicinity of. or within. subspecies- or serovar-specific epitopes and. therefore. are likely to modify their antigenic properties. For instance, the $\mathrm{Ala}_{311} \rightarrow \mathrm{Thr}\left(\mathrm{G}_{997} \rightarrow \mathrm{A}\right)$ variation between the D/IC-Cal-8 and Da/TW-448 VDIV sequences is clearly involved in the antigenic differences between these two serovars. Indeed, this variation was first reported by Lampe et al. ${ }^{43}$ together with another amino acid variation in VDI. It was also identified by Dean et $a l^{*}$ who, in agreement with results presented here and elsewhere. ${ }^{14}$ did not observe any difference in VDI. As we have now determined the complete sequence of the four VDs for the two serotypes. we can postulate that the observed amino acid variation in VDIV is the only determinant accounting for the differentiation of $D$ from Da strains with MAbs. These conclusions are in agreement with the immunological data of Lampe et al. ${ }^{43}$ and with the VDIV epitope mapping studies of Vretou et al. ${ }^{32}$ The $\mathrm{Ala}_{304} \rightarrow \mathrm{Thr}\left(\mathrm{G}_{976} \rightarrow \mathrm{A}\right)$ substitution is the only difference located in the VDs which differentiates the five strains of group D2 from the other strains of serovar D. Again. this substitution was observed previously by Lampe et al. ${ }^{1: 3}$ in four strains (labelled $D$ ) that were distinguished from the D strains by a negative reaction with a subspecies-specific MAb. This antigenic feature had been identified also between the D2 and D strains from Greece (strains D/Ev-688 and D/Ev-857 and strain D/Ev-389, respectively; table II) with different MAbs (E. Vretou. unpublished data). As this is the only variation in the VDs between the

\section{References}

1. Grayston JT, Wang S-P. New knowledge of Chlamydiae and the diseases they cause. I Infect Dis 1975: 132: 87-105.

2. Wang S-P, Kuo C-C. Barnes RC. Stephens RS, Grayston JT Immunotyping of Chlamydia trachomatis with monoclonal antibodies. J Infeet Dis 1985: 152: 791-800.

3. Wang S-P. Grayston JT. Three new serovars of Chlamydio trachomatis: Da. Ia, and L2a. J Infect Dis 1991: 163: 403-405.

4. Zhang Y-X. Stewart S, Joseph T. Taylor HR, Caldwell HD. Protective monoclonal antibodies recognize epitopes located on the major outer membrane protein of Chlamydia trachomatis. J Immunol 1991: 138: 575-581.

5. Baehr W. Zhang Y-X. Joseph $\mathrm{T}$ et al. Mapping antigenic domains expressed by Chlamydia trachomatis major outer membrane protein genes. Proc Natl Acad Sci USA 1988: 85: $4000-4004$.

6. Stephens RS, Wagar EA. Schoolnik GK. High-resolution mapping of serovar-specific and common antigenic determinants of the major outer membrane protein of Chlamydia trachomatis. J Exp Med 1988: 167: 817-831.

7. Su H. Morrison RP. Watkins NG. Caldwell HD. Identification and characterization of $\mathrm{T}$ helper cell epitopes of the major outer membrane protein of Chlamydia trachomatis. $J$ Exp Med 1990: 172: 203-212.

8. Dean D, Patton M. Stephens RS. Direct sequence evaluation of the major outer membrane protein gene variant regions of Chlamydia trachomatis subtypes $\mathrm{D}^{\prime}, \mathrm{I}^{\prime}$. and $\mathrm{L}_{2}^{\prime}$. Infect Immun 1991: 59: 1579-1582.

9. Hamilton PT. Malinowski DP. Nucleotide sequence of the major outer membrane protein gene from Chlamydia trachomatis serovar H. Nucleic Acids Res 1989: 17: 8366.

10. Hayes LJ, Clarke IN. Nucleotide sequence of the major outer membrane protein gene of Chlamydia trachomatis strain A/SA1/OT. Nucleic Acids Res 1990; 18: 6136. three groups of serovar D strains, it must account for this antigenic variability. The fact that residue 304 lies in a region which reacts in vivo with neutralising antibodies ${ }^{4}$ together with our demonstration that this variation is found in a stable group of strains within serovar D suggest the emergence of a new epitope. Thus, Ala $\rightarrow$ Thr changes at positions 304 and 311 might represent the molecular basis of an antigenic drift of surface-exposed epitopes for the $\mathrm{Da}^{32}$ and the D2 strains to evade the immune pressure of the host. ${ }^{44}$ Similarly, the $\mathrm{Ala}_{290} \rightarrow \mathrm{Thr}$ and $\mathrm{Ala}_{309} \rightarrow \mathrm{Arg}$ substitutions in VDIV which characterise the variant strain $\mathrm{E} / \mathrm{C}-31$ are localised within a B-complex subspecies-specific epitope. ${ }^{4.645}$ Thus, these non-conservative amino acid substitutions might create new antigenic determinants and corroborate the description of the serovariants described by Suchland and Stamm. ${ }^{46}$

To our knowledge, DGGE analysis of PCR products has not previously been applied to bacteria. Its application to chlamydia as well as its recent utilisation for the human immunodeficiency virus ${ }^{47}$ highlight its potential for characterisation of microbial DNA sequence diversity.

We thank E. Vretou for kindly providing strains from Greece as well as unpublished data, and C. C. Kuo and E. Peterson for kindly providing some of the strains. We thank M. A. Corvoisier for her invaluable help in preparing this manuscript. This work was supported in part by a grant from the co-operative action between the Caisse Nationale d'Assurance Maladie des Travailleurs Salariés (CNAMTS) and the Institut National de la Santé et de la Recherche Médicale (INSERM)

11. Hayes LJ, Pickett MA, Conlan JW et al. The major outermembrane proteins of Chlamydia trachomatis serovars A and B: intra-serovar amino acid changes do not alter specificities of serovar-and $\mathrm{C}$ subspecies-reactive antibodybinding domains. J Gen Microbiol 1990; 136: 1559-1566.

12. Peterson EM, Markoff BA, de la Maza LM. The major outer membrane protein nucleotide sequence of Chlamydia trachomatis, serovar E. Nucleic Acids Res 1990; 18: 3414.

13. Pickett MA, Ward ME, Clarke IN. Complete nucleotide sequence of the major outer membrane protein gene from Chlamydia trachomatis serovar L1. FEMS Microbiol Lett 1987; 42: 185-190.

14. Sayada C, Denamur E, Elion J. Complete sequence of the major outer membrane protein-encoding gene of Chlamydia trachomatis serovar Da. Gene 1992; 120: 129-130.

15. Stephens RS, Sanchez-Pescador R, Wagar EA, Inouye C, Urdea MS. Diversity of Chlamydia trachomatis major outer membrane protein genes. $J$ Bacteriol 1987; 169. $3879-3885$.

16. Yuan Y. Zhang Y-X, Watkins NG., Caldwell HD. Nucleotide and deduced amino acid sequences for the four variable domains of the major outer membrane proteins of the 15 Chlamydia trachomatis serovars. Infect Immun 1989; 57 : 1040-1049.

17. Zhang Y-X, Morrison SG, Caldwell HD. The nucleotide sequence of major outer membrane protein gene of Chlamydia trachomatis serovar F. Nucleic Acids Res 1990; 18: 1061 .

18. Lucero ME, Kuo CC. Neutralization of Chlamydia trachomatis cell culture infection by serovar-specific monoclonal antibodies. Infect Immun 1985; 50: 595-597.

19. Frost EH, Deslandes S, Veilleux S, Bourgaux-Ramoisy D. Typing Chlamydia trachomatis by detection of restriction fragment length polymorphism in the gene encoding the major outer membrane protein. J Infect Dis 1991; 163: 1103-1107. 
20. Rodriguez P, Vekris A, de Barbeyrac B, Dutihl B, Bonnet J, Bebear $\mathrm{C}$. Typing of Chlamydia trachomatis by restriction endonuclease analysis of the amplified major outer membrane protein gene. J Clin Microbiol 1991; 29: 1132-1136.

21. Sayada C, Denamur E, Orfila J, Catalan F, Elion J. Rapid genotyping of the Chlamydia trachomatis major outer membrane protein by the polymerase chain reaction. FEMS Microbiol 1991; 83: 73-78.

22. Dean D, Schachter J, Dawson CR, Stephens RS. Comparison of the major outer membrane protein variant sequence regions of the $\mathrm{B} / \mathrm{Ba}$ isolates: a molecular epidemiologic approach to Chlamydia trachomatis infections. $J$ Infect Dis $1992 ; 166: 383-392$.

23. Poole E, Lammont I. Chlamydia trachomatis serovar differentiation by direct sequence analysis of the variable segment 4 region of the major outer membrane protein gene. Infect Immun 1992; 60: 1089-1094.

24. Fischer SG, Lerman LS. Separation of random fragments of DNA according to properties of their sequences. Proc Natl Acad Sci USA 1980; 77: 4420-4424.

25. Fischer SG, Lerman LS. DNA fragments differing by singlebase-pair substitutions are separated in denaturing gradient gels: correspondence with melting theory. Proc Natl Acad Sci USA 1983; 80: 1579-1583.

26. Myers RM, Fischer SG, Lerman LS, Maniatis T. Nearly all single base substitutions in DNA fragments joined to GCclamp can be detected by denaturing gradient gel electrophoresis. Nucleic Acids Res 1985; 13: 3131-3145.

27. Myers RM, Maniatis T, Lerman LS. Detection and localization of single base changes by denaturing gradient gel electrophoresis. Methods Enzymol 1987; 155: 501-527.

28. Lerman LS, Silverstein K. Computational simulation of DNA melting and its application to denaturing gradient gel electrophoresis. Methods Enzymol 1987; 155: 482-501.

29. Sheffield VC, Cox DR, Lerman LS, Myers RM. Attachment of a 40-base pair $\mathrm{G}+\mathrm{C}$-rich sequence (GC-clamp) to genomic DNA fragments by the polymerase chain reaction results in improved detection of single-base changes. Proc Natl Acad Sci USA 1989; 86: 232-236.

30. Barnes RC, Rompalo AM, Stamm WE. Comparison of Chlamydia trachomatis serovars causing rectal and cervical infections. J Infect Dis 1987; 156: 953-958.

31. Moncan T, Eb F, Orfila J. Monoclonal antibodies in serovar determination of 53 Chlamydia trachomatis isolates from Amiens, France. Res Microbiol 1990; 141 : 695-701.

32. Vretou E, Mentis A, Psarrou E, Tsoumaris L, Conidou G, Spiliopolou D. Unusual prevalence of the rare serovar $\mathrm{Da}$ of Chlamydia trachomatis in Greece detected by monoclonal antibodies. Sex Transm Dis 1992; 19: 78-83.

33. Mullis KB. The polymerase chain reaction in an anemic mode: how to avoid cold oligodeoxyribonuclear fusion. $P C R$ Methods Applic 1991; 1: 1-4.

34. Rychlik W, Rhoads RE. A computer program for choosing optimal oligonucleotides for filter hybridization, sequencing and in vitro amplification of DNA. Nucleic Acids Res 1989; 17: 8543-8551.

35. Attree $\mathrm{O}$, Vidaud $\mathrm{D}$, Vidaud $\mathrm{M}$, Amselem $\mathrm{S}$, Lavergne JM, Goossens M. Mutations in the catalytic domain of human coagulation factor IX: rapid characterization by direct genomic sequencing of DNA fragments displaying an altered melting behavior. Genomics $1989 ; 4$ : 266-272.

36. Sanger F, Nicklen S, Coulson AR. DNA sequencing with chainterminating inhibitors. Proc Natl Acad Sci USA 1977; 74 : 5463-5467.

37. Noll WW, Collins M. Detection of human DNA polymorphisms with a simplified denaturing gradient gel electrophoresis technique. Proc Natl Acad Sci USA 1987; 84: 3339-3343.

38. Traystman MD, Higuchi M, Kasper CK, Antonarakis SE, Kazazian $\mathrm{HH}$. Use of denaturing gradient gel electrophoresis to detect point mutations in the factor VIII gene. Genomics 1990; 6: 293-301.

39. Kogan S, Gitschier J. Mutations and a polymorphism in the factor VIII gene discovered by denaturing gradient gel electrophoresis. Proc Natl Acad Sci USA 1990; 87: 2092-2096.

40. Cai SP, Kan YW. Identification of the multiple $\beta$-thalassemia mutations by denaturing gradient gel electrophoresis. $J$ Clin Invest $1990 ; 85: 550-553$.

41. Tachdjian G, Benabdennebi M, Guidal C, Sayada C, Lapouméroulie C, Elion J. Analysis of the $5^{\prime}$ flanking sequence of the gamma globin gene by denaturing gradient gel electrophoresis confirms the heterogeneity of the Bantu $\beta^{s}$ haplotype. Human Genet 1992; 90: 23-26.

42. Ferec C, Audrezet MP, Mercier B et al. Detection of over $98 \%$ cystic fibrosis mutations in a Celtic population. Nature Genetics 1992; 1: 188-191.

43. Lampe MF, Suchland RJ, Stamm WE. Nucleotide sequence of the major outer membrane protein of the Chlamydia trachomatis D serovar and two D variants. In: Bowie WR. Caldwell HD, Jones RP et al. (eds) Chlamydial infections. Proceedings of the Seventh International Symposium on Human Chlamydial Infections. Cambridge, Cambridge University Press. 1990: 97-100.

44. Van der Ploeg LHT, Gottesdiener K, Lee MG-S. Antigenic variation in African trypanosomes. Trends Genet 1992; 8: $452-457$.

45. Zhong G, Reid RE, Brunham RC. Mapping antigenic sites on the major outer membrane protein of Chlamydia trachomatis with synthetic peptides. Infect Immun 1990; 58: 1450-1455.

46. Suchland RJ, Stamm WE. Simplified microtiter cell culture method for rapid immunotyping of Chlamydia trachomatis. $J$ Clin Microbiol 1991; 29: $1333-1338$.

47. Anderson B, Ying JH, Lewis DE, Gibbs RA. Rapid characterization of HIV-1 sequence diversity using denaturing gradient gel electrophoresis and direct automated DNA sequencing of PCR products. PCR Methods Applic 1993; 2: 293-300. 